\title{
Bonnat, Linard, Le Bourg-d'Hem
}

\section{Christine Serre}

\section{OpenEdition \\ Journals}

Édition électronique

URL : http://journals.openedition.org/adlfi/5153

ISSN : 2114-0502

Éditeur

Ministère de la culture

\section{Référence électronique}

Christine Serre, "Bonnat, Linard, Le Bourg-d'Hem », ADLFI. Archéologie de la France - Informations [En ligne], Limousin, mis en ligne le 01 mars 2006, consulté le 01 mai 2019. URL : http:// journals.openedition.org/adlfi/5153

Ce document a été généré automatiquement le 1 mai 2019.

(c) Ministère de la Culture et de la Communication, CNRS 


\title{
Bonnat, Linard, Le Bourg-d'Hem
}

\author{
Christine Serre
}

Identifiant de l'opération archéologique : 2663

Date de l'opération : 2006 (PR)

1 Au cours de l'année 2005, le village de Nioux, qui se trouve sur la commune de Linard, avait dévoilé des indices d'habitat gallo-romain et médiéval. Une villa a été à peu près localisée et prospectée. De nombreux tessons de poteries médiévales ont été découverts, ainsi que quelques poterie antiques. Le site a donc clairement été réutilisé au Moyen Âge. À l'emplacement d'une parcelle appelée « les Fours » ont été découverts des morceaux de métal fondu. Au niveau d'une parcelle appelée "le Soudrin", la découverte d'un souterrain est signalée au XIX ${ }^{e}$ s., contenant des poteries. Ce terrain a été minutieusement prospecté après les labours. Seul un petit morceau de poterie décoré avec des plumes d'oiseau a été retrouvé. Les habitants de Nioux parlent encore de la route pavée qui traversait leur village et la légende veut que Nioux ait été un véritable bourg. Toujours sur Linard, deux fiches inédites ont été établies dont l'une concerne un silex taillé trouvé au cours de la prospection.

2 Concernant la commune de Bonnat, il n'a pas été possible de retrouver l'emplacement exact de la nécropole gallo-romaine de Coussa: aux dires du propriétaire du terrain, celle-ci a été détruite lors de l'extraction d'uranium sur le site. Un coffre a cependant été sauvegardé et se trouve dans le bourg. Dans ce même village, des murs d'une villa ont nettement été repérés dans une pâture. Cette dernière est longée par une voie empierrée où des maçonneries sont visibles. Seules des observations effectuées au moment d'une nouvelle mise en pâture permettraient de compléter le plan de cet habitat. 
INDEX

Index chronologique : Empire romain, ép. contemporaine, Moyen Âge

operation Prospection (PR), Prospection diachronique (PRD)

Index géographique : Limousin, Creuse (23), Bonnat

Thèmes : acquisition de ressource naturelle, céramique gallo-romaine, céramique médiévale, coffre, habitat groupé, nécropole, route, silex, souterrain, villa

\section{AUTEURS}

CHRISTINE SERRE

Bénévole 